an alpha-blocker such as phentolamine should be the first choice in the management of hypertension complicating clonidine overdose.

We should also like to take issue with the recommendation that forced frusemide diuresis is an effective means of removing clonidine. In normal individuals given $300 \mu \mathrm{g}$ of clonidine either orally or intravenously we have found that $39-48 \%$ of the dose is excreted unchanged in the urine in the first 24 hours. In addition, a variable amount of extrarenal elimination occurs. In the first case described by Dr Hunyor and his colleagues $47 \%$ of the ingested dose was excreted in the first 24 hours, and this is what we would have expected without the use of frusemide. Although we have no experimental data on the effect of frusemide on clonidine excretion, we doubt if it would alter the rate of elimination if an adequate unine flow was maintained.

L M H WING

D S DAVIES

J L REID

C T DOLLERY

Department of Clinical Pharmacology,

Royal Postgraduate Medical School,
London $W 12$

1 Dollery, C T, et al, Clinical Pharmacology and 2 Kobinger, W, and Walland, A, ArzneimittelforKobinger, W, and What $1967,17,292$.
schung,

Enteric-coated aspirin overdose and gastric perforation

SIR,-The report by Dr $\mathbf{R} J$ Farrand and others (11 October, p 85) of a case of gastric perforation following the ingestion of an overdose of Safapryn suggests that sufficient aspirin may leach out of enteric-coated aspirin cores in the stomach itself to cause irritation of the gastric mucosa, erosions, and perforation. The post-mortem photograph iilustrating the case clearly shows erosions of the gastric mucosa at points where entericcoated aspirin cores were in contact with it, but I feel that attention should be drawn to the fact that mechanical factors were operating in this case which would not be present in the more usual situation of a patient taking 2-4 tablets of Safapryn at a time.

The post-mortem report on this patient stated that "67 intact whole tablets were present in the stomach. The tablets were all of similar plain white appearance, but showed varying degrees of bile-staining and seven were slightly thicker. One 1913 silver threepenny coin was also found, showing heavy bile-staining." The pathologist's comment was as follows. "Coins pass through the gastrointestinal tract without delay, so the threepenny piece must have been taken with the tablets. The Safapryn would have been ingested 6-48 hours before death. They could not have accumulated at six a day over 11 days. The chest and abdominal pains she had in the early hours of 18 April could have been caused by irritation of the stomach by the ingested tablets."

The number of tablets taken was large and they were in the stomach for many hours before death. During this time they must have been exposed to a certain amount of attrition by mutual friction and by friction against the silver coin. This could have been enough to chip the protective enteric coating off many of them, exposing small areas of aspirin which, while insignificant for the purpose of absorption (no free aspirin was found in the stomach), nevertheless presented sites where contact could be made between the gastric mucosa and concentrated sources of aspirin. The conditions were not the same, therefore, as those found following the therapeutic administration of Safapryn.

In a recent study 10 patients were given four tablets of Safapryn and a marked table consisting of a barium sulphate core with an enteric coating identical with that used in Safapryn. The course of the marker tablet was followed by serial $x$-ray examination, and in none of these 10 patients did the marker disappear until it had reached the ileum or jejunum. By inference, therefore, no aspirin was released in the stomach or duodenum. This suggests that release of aspirin in the stomach from Safapryn tablets is unlikely in the absence of other factors such as the mechanical one mentioned above. In the case reported by Dr Farrand and his colleagues still other factors may also have played a part: the patient had been, for an unspecified time, treated with phenylbutazone, which is a well-known gastric irritant and may have modified the state of the gastric mucosa.

F J A BATEMAN Medical Director

Sandwich, Ken Pfizer Lod

** We showed this letter to Dr Farrand whose reply is printed below.

SIR,-How much room for speculation is there in a "short report"? I consulted Pfizer Ltd but did not think a small coin was of significance. Likewise, I did not report tests carried out by the Manchester Regional Quality Control Laboratory on Safapryn tablets from the batch used. The tablets failed the $B P$ disintegration test as they did not disintegrate completely at $\mathrm{pH}$ 6.8. Pfize Ltd confirmed the results and commented on a tendency for intestinal disintegration time to lengthen with storage. Perhaps there is significant variation in the enteric coating The coats of the tablets from this patient still appear intact and, once exposed, aspirin is rapidly soluble. We have filled a mixer with Safapryn tablets, the coin in question, and simulated gastric juice, and after 24 hours mixing the enteric coats remain intact.

I might envy Dr J M Gumpel (1 November, p 287) his clearcut assumptions, but if patients were simple there would be no call for thought. We enjoyed speculating abou possibilities in the case reported and are sorry that Dr Gumpel seems immediately to jump to conclusions. We hesitated to blame paracetamol for gastric perforations because inquiries indicated that the overdose was taken about 24 hours before death and the liver appeared normal. After a fatal paracetamol overdose most patients appear well for the first three days, after which signs of liver failure develop. ${ }^{1}$ The plasma half life of paracetamol, even in overdose, has been found to be only about four hours, ${ }^{2}$ so that the toxic blood level is gone long before death occurs due to paracetamol. We should like to know when Dr Gumpel has seen gastric perforation following acute para- cetamol overdose: his apocrypha of paracetamol toxicity is more extensive than ours. We hesitated to blame phenylbutazone because none was detectable in the stomach or blood, there was no history of phenylbutazone intolerance, and we did not accept the overdose as mere coincidence.

I am grateful to your correspondents' contributions to a complex case. We tried to eliminate the impossible and what remained, however improbable, I think must be the truth.

I am grateful to $\mathrm{Mr} \mathrm{N}$ W Blacow for the pharmaceutical results.

R J FARRAND

Department of Pathology,

Hope Hospital,

1 Clark, R, et al, Lancet, 1973, 1, 66.

Proudfoot, A T, and Wright, N, British Medical
fournal, 1970, 3, 577.

\section{A safer antidepressant?}

SIR,-Tricyclic antidepressants are among the most toxic of the commonly used psychotropic drugs. ${ }^{1}$ The first recorded fatal overdosage of imipramine took place within a year of its introduction in 1959, while in 1973, out of 2914 deaths from suicidal, aocidental, and "undetermined" poisoning, some $9 \%$ were attributable to tricyclic drugs. ${ }^{2}$ A study of the figures for previous years indicates that, at a conservative estimate, the proportion of suicidal poisoning due to tricyclics increased by more than seven times between 1965 and 1973, while antidepressant prescribing during the same period increased by only $2 \frac{1}{2}$ times. It seems that depressed and suicidal patients are more aware of tricyclic toxicity than are many doctors.

Viloxazine (Vivalan) is a new antidepressant chemically unrelated to tricyclic compounds and apparently much less toxic than them. In the year since its general release no fatalities have been reported, and an uneventful recovery from an overdose of $6.5 \mathrm{~g}$ is on record. ${ }^{4}$ In contrast, according to Brophy, ${ }^{1}$ the largest recorded non-fatal ingestion of amitriptyline is $4.7 \mathrm{~g}$. Animal studies also indicate the relative safety of viloxazine, for which the median lethal dose $\left(\mathrm{LD}_{5_{0}}\right)$ by mouth in mice is $1000 \mathrm{mg} / \mathrm{kg}^{5}$ compared with $289 \mathrm{mg} / \mathrm{kg}$ for amitriptyline. ${ }^{6}$

It is not my purpose to suggest that viloxazine should be used with the abandon which characterises much current tricyclic prescribing. Indeed, I remain rather sceptical of the value of antidepressants, which have had no obvious beneficial effect on either the suicide rate or the number of admissions for depression. I do believe, however, that if viloxazine were prescribed a little more and tricyclics a good deal less we might be spared the sad and ironic spectacle of patients killing themselves with tablets which have been prescribed in order to make them happy.

COLIN BREWER

Midland Nerve Hospital,

Birmingham

Brophy, J, Archives of General Psychiatry, 1967, Pharmaceutical fournal, 1975, 214, 249.

3 Pharmaceutical fournal, 1975, 214, 249.

Hanning, C D. Personal communication, 1975.

5 Mallion, K B, et al, Nature. 1972, 238, 157.

Barnes, C D, and Etherington, L G, Drug Dosage in Laboratory Animals, 2nd edn. Berkeley, 